\title{
Associationj of TSHR Gene Single Neucleotide Intronic Polymorphism with the Risk of Hypothyroid and Hyperthyroid Disorders in Yazd Province.
}

Fahime Naghibi

Faculty of Science and Engineering, Science and Arts University

Seyed Mohsen Miresmaili

Faculty of Science and Engineering, Science and Arts University

Amaneh Javid ( $\nabla$ a-javid@ut.ac.ir)

Faculty of Science and Engineering, Science and Arts University

\section{Research Article}

Keywords: TSHR, intronic, polymorphism, hypothyroid

Posted Date: January 7th, 2022

DOI: https://doi.org/10.21203/rs.3.rs-1229601/v1

License: @ (i) This work is licensed under a Creative Commons Attribution 4.0 International License. Read Full License 


\section{Abstract}

The present study was carried, for the first time, out to evaluate the association of rs2268458 polymorphism, biochemical and environmental factors on hypothyroid and hyperthyroid disorders in thyroid patients and healthy individuals in Yazd province, Iran. In this study, blood samples were collected from a total of 100 cases, including 60 hypothyroid, 20 hyperthyroidism individual cases and 20 normal individuals. DNA was extracted from blood samples and the rs2268458 single neucleotide intronic polymorphism was evaluated using RFLP-PCR. The results have shown that 59 cases were homozygote (TT), 40 cases heterozygote (TC) with one homozygote (CC) case, as follows; A total of 25 (TT) homozygote cases were observed to be hypothyroid females, 20 (TC) heterozygote cases of hypothyroid females, 7 (TT) homozygote male hypothyroid cases and 7 (TC) heterozygote male hypothyroid cases and 1 (CC) homozygote male hypothyroid patient. While, 7 (TT) homozygote hyperthyroid female cases, 8 (TC) heterozygote hyperthyroid female cases, were also observed. According to our study, heterozygote cases (TC) showed less severe symptoms, while homozygote cases (TT) showed no serious symptoms and the (CC) homozygote case (CC) showed severe thyroid abnormality symptoms. So, it can be concluded that the TSHR-related rs2268458 polymorphism is associated with hypothyroidism and hyperthyroidism in the male and female polulations of Yazd Province, Iran and $\mathrm{C}$ allele can be a risk factor for some physio-biochemical and hormonal imbalance in the thyroid disorder patients.

\section{Introduction}

The present study was carried, for the first time, out to evaluate the association of rs2268458 polymorphism, biochemical and environmental factors on hypothyroid and hyperthyroid disorders in thyroid patients and healthy individuals in Yazd province, Iran. In this study, blood samples were collected from a total of 100 cases, including 60 hypothyroid, 20 hyperthyroidism individual cases and 20 normal individuals. DNA was extracted from blood samples and the rs2268458 single neucleotide intronic polymorphism was evaluated using RFLP-PCR. The results have shown that 59 cases were homozygote (TT), 40 cases heterozygote (TC) with one homozygote (CC) case, as follows; A total of 25 (TT) homozygote cases were observed to be hypothyroid females, 20 (TC) heterozygote cases of hypothyroid females, 7 (TT) homozygote male hypothyroid cases and 7 (TC) heterozygote male hypothyroid cases and 1 (CC) homozygote male hypothyroid patient. While, 7 (TT) homozygote hyperthyroid female cases, 8 (TC) heterozygote hyperthyroid female cases,were also observed. According to our study, heterozygote cases (TC) showed less severe symptoms, while homozygote cases (TT) showed no serious symptoms and the (CC) homozygote case (CC) showed severe thyroid abnormality symptoms. So, it can be concluded that the TSHR-related rs2268458 polymorphism is associated with hypothyroidism and hyperthyroidism in the male and female polulations of Yazd Province, Iran and $\mathrm{C}$ allele can be a risk factor for some physio-biochemical and hormonal imbalance in the thyroid disorder patients.

The thyroid gland influences almost all of the metabolic processes in human body. Thyroid-related disorders can range from a small, harmless goiter (enlarged thyroid gland) that needs no specific treatment to life-threatening cancer. Thyroid diseases rank as the most prevalent endocrine disorders after diabetes[1]. The thyroid gland secretes hormones that help regulate the body's metabolism. According to arecent study, thyroid-related diseases affect 200 million people worldwide, of which about $60 \%$ are unaware of their disease. There are several factors involved in thyroid dysfunction, the most common of which is iodine deficiency that is estimated to be affecting 2 billion individuals worldwide and is thought to cause primary hypothyroidism [2]. The most common cause of hypothyroidism is chronic autoimmune thyroiditis, also known as Hashimoto's disease. High concentrations of anti-thyroid antibodies (predominantly thyroid peroxidase (TPO) antibodies and anti-thyroglobulin antibodies) are present in most patients with autoimmune thyroiditis [3].

Thyroid hormones play a critical role in human physiology and metabolism. Thyroid disorders are defined as a group of pre-dominantly biochemical dysfunctions because of the lack their symptom specificity [4]. Overt or clinical primary hypothyroidism is defined as the disorder with above-the-range concentrations of thyroid-stimulating hormone (TSH) and below-reference concentrations of free-thyroxine. While, mild or subclinical hypothyroidism accompanies above-the-range TSH and normal free-thyroxine levels; and is commonly regarded as a sign of early thyroid failure. In patients with subclinical hypothyroidism, TPO antibodies' testing helps to predict the progression to overt hypothyroidism [5].

Thyroid-releasing hormone (TRH) is secreted by hypothalamus gland of central nervous system (CNS) that promotes the secretion of thyroid stimulating hormone (TSH) by pituitary gland [6]. TSH regulates thyroid function and stimulates the secretion of triiodothyrine (T3) and thyroxine (T4) hormones by the thyroid gland There is inadequate knowledge about the individuals with genetic variations in thyroid hormone metabolism, which has led a number of questions unanswered about thyroid dysfunctions and how to handle them [7].

The TSH receptor (TSHR) is a 7-transmembrane domain G protein-coupled receptor (GPCR) that is a major thyroid-gland regulator and is key autoantigen in autoimmune thyroid diseases (AITDs) [8]. The TSHR gene is located on chromosome $14 \mathrm{q}$ and is considered to be related to diseasespecific functions. Genetic variants in the TSHR gene were recognized to be associated with the risk of thyroid diseases [9-11]. Previous studies have shown that choromosome 14 is associated with thyroid disorders; particularly hypothyroidism and the most important gene-regions are $35 \mathrm{Mbp}$, $95 \mathrm{Mbp}$ and $93 \mathrm{Mbp}$, in proximity to the rs2268458 single-neucleotide polymorphism (SNP) [12-15] ,which is located on intron 1 of TSHR gene.

In this study, we attempted to find the association of SNP rs2268458 at the TSHR gene locus with hypothyroidism and hyperthyroidism in male and female populations of Yazd Province, Iran. Furthermore, we analyzed the association between genotypes and AITD

\section{Material And Methods}


Study population. A population-based cohort study was performed between 2019-2020 in Yazd, a metropolitan city of Central Iran. In short, male and female $(n=150)$ hypothyroid and hyperthyroid patients, and 70 healthy candidates were selected and acquired the informed consent to participate in the study. The present study was approved by Human Research Ethics Committee; Academic Center for Education, Culture and Research (ACECR), Iran and the research was conducted in accordance with the Declaration of Helsinki. These patients were examined by a trained general practitioner and an endocrinologist. All data including demography, age, past history of thyroid and any other disorders, smoking history and use of medications were collected. The patients were also examined for goiter or nodules. The body mass index (BMI) was calculated by dividing weight (kg) to the height square $\left(\mathrm{m}^{2}\right)$.

Blood sample collection and genomic DNA extraction. Fasting blood samples were collected from hypo-and hyper-thyroid patients who matched the study criteria. Blood $(5 \mathrm{~mL})$ was withdrawn and transferred into plain tubes $(3 \mathrm{~mL})$ and EDTA tubes $(2 \mathrm{~mL})$. The blood samples in the plain tube were centrifuged after $30 \mathrm{~min}$ of sampling for serum collection, which was then stored at $-20^{\circ} \mathrm{C}$ and stored for further analysis. Samples were assayed in duplicate and the mean of the paired results were analyzed. EDTA tubes were stored at $-20^{\circ} \mathrm{C}$ for genomic DNA extraction. Genomic DNA was extracted and purified from whole peripheral blood samples using Blood Genomic DNA Extraction Kit (Pars Tous Biotechnology Co; Mashhad, Iran). DNA sample were stored at $-86^{\circ} \mathrm{C}$ in aliquots for further analysis.

Biochemical analysis of blood samples. Blood samples (5-10 ml blood, mixed with EDTA (each ml of blood was mixed with $60 \mu \mathrm{l}$ of EDTA)) were taken and T3, T4, and TSH measurements were carried out. Serum total T4 and T3 were analyzed by radioimmunoassay. Normal range of T4 concentration was $4.5-12.0 \mu \mathrm{g} / \mathrm{dL}$ and T3 normal concentration was $0.92-2.79 \mathrm{nmol} / \mathrm{L}$. Serum TSH concentration was assessed by immunoradiometric assay. The normal range for TSH was 0.3-3.6 mlU/L. The hypothyroid individuals were described as follows: overt (clinical) hypothyroidism (TSH > $10 \mathrm{mIU} / \mathrm{L}$ ), subclinical hypothyroidism ( $10 \geq \mathrm{TSH}>3.6 \mathrm{mIU} / \mathrm{L}$ ). While, hyperthyroidism was described as overt (or clinical) hyperthyroidism (TSH level < $0.1 \mathrm{mIU} / \mathrm{L}$ and total T4 $>12 \mu \mathrm{g} / \mathrm{dL}$ and/or total T3 $>2.79 \mathrm{nmol} / \mathrm{L}$ ) and subclinical hyperthyroidism (TSH $<0.3 \mathrm{mlU} / \mathrm{L}$ and total T4 and total T3 within normal range, $4.5-12.0 \mu \mathrm{g} / \mathrm{dL}$ and $0.92-2.79 \mathrm{nmol} / \mathrm{L}$, respectively).

TSHR-SNP-rs2268458 analysis by PCR-RFLP. PCR amplification of the TSHR gene was carried out using PCR Master Mix (Taq DNA Polymerase Master Mix, Ampliqon A/S, Odense, Denmark). Based on the analysis of [16], we examined TSHR-SNP-rs2268458, located in intron 1, using standard RFLP-PCR protocol [16]. Human genomic DNA (about $25 \mathrm{ng}$ ) was amplified by PCR machine and 415-bp products were generated, as described above. The primer sequences used for this analysis are as follows:

\section{F: 5' CTAACCAGCAGAGGGAGCAC3'}

\section{R: 5' CCACTGCTTAAAGCCCAGAT3'}

These primers flanked the DNA segment in TSHR gene intron 1. PCR sample consisted of $0.2 \mathrm{mg}$ genomic DNA, $0.5 \mathrm{~mL}$ Taq polymerase, $0.5 \mu \mathrm{M}$ primary forward, $0.5 \mu \mathrm{M}$ primary reverse and $200 \mathrm{mM}$ dNTP. The DNA samples were amplified for 35 cycles with initial denaturation at $94^{\circ} \mathrm{C}$ for 5 minutes, annealing cycle at $53^{\circ} \mathrm{C}$ for 30 seconds, extension cycle at $72^{\circ} \mathrm{C}$ for 30 seconds, denaturation at $94^{\circ} \mathrm{C}$ for 30 seconds and and final extension was carried out at $72^{\circ} \mathrm{C}$ for 7 minutes $[17,18]$. Concentration and DNA purity was calculated using nanodrop with a purity range of $1.8-2.0$ (ScanDrop ${ }^{2}$, Analytik Jena, Germany). The final amplification mixtures were then electrophoresed on $2 \%$ agarose gel for 45 minutes at 90 Volts. Visualization of the DNA fragment bands was done using Gel documentation system. Then, $8 \mu \mathrm{L}$ of PCR products was digested for 2 hours in $10 \mu \mathrm{L}$ total volume with the restriction endonuclease Alu I (Therno Fisher Scientific Inc.) overnight according to the manufacturer's instructions. RFLP-PCR was carried out to varify the wild allele and the rs2268458 SNP variant with Alu I restriction enzyme along with a nondigested DNA control. After digestion, the digested fragments were loaded onto $2 \%$ agarose gel and visualized by ethidium bromide and gel documentation to carry out genotype pattern analysis. Since Alu I digestion determines AGTT versus AGCT, this allowed the determination of each individual's hetero- or homogenotype.

Exclusion criteria. There are several pathological, normal physiological conditions and daily habits that can interfere with hypothyroidism and hyperthyroid cases. Such cases were excluded from this study such as heart disease, hypertension, diabetes mellitus, pregnancy, and smoker individuals.

Statistical analysis. The resultant data were analyzed using SPSS (version 22.0). In bivariate analysis, the numeric variables were calculated using $t$-test when there was a normal distribution and Mann Whitney/ KruskalWallis test for abnormally distributed data. The bivariate analysis for categorical variables used $\chi^{2}$-squared test. For the multivariate determination, the logistic regression was used as the dependent variables were also categorical variables.

\section{Results}

The extracted DNA was clear and not fragile (Fig. 1A). PCR product of TSHR locus showed a single 162 bp band (Fig. 1B). Fig. 1(C) shows the pattern of PCR products on agarose gel electrophoresis, related to TSHR gene (162 bp band) after being restricted by Alu I enzyme. The normal (bands B, C, N, 0 and $P$ ), the hyperthyroid (bands $F$ and $R$ ) and the hypothyroid cases (bands $A, D, E, G, H, I, V, J, K, L, M$ and $S$ ) were analyzed in this experiment. Heterozygote genotypes (TC) with showed by 162, 100 and 62 bp bands in D, E, F, G, I, J, L, N, M and S samples. Homozygote genotypes (TT) with characterized by a 162 bp band in $A, B, C, H, K, O, P, Q$ and R samples. Homozygote genotype (CC) was shown with 100 and 62 bp bands in $V$ sample. The PCR products were treated by Alu1 enzyme. According to Fig. 2, the PCR products were treated by Alu1 enzyme. The B,C,N,O,P cases were normal, the $R$ and $F$ cases were hyperthyroidism and the $A, D, E, G, H, I, V, J, K, L, M, S$ were hypothyroid cases. The $D, E, F, G, I, J, L, N, M, S$ cases were heterozygote (TC) and

Page $3 / 9$ 
they have 3 bands : 162, 100 and 62 bp. A,B,C,H,K,O,P,Q,R casese were homozygote (TT) and have a single 162 bp band and the $V$ case is homozygote (CC) and has 100 and 62 bp bands and L stands for Ladder which all the bands are compared with it.

RFLP-PCR analysis of TSHR rs2268458 intronic polymorphism. The RFLP-PCR analysis of DNAs, extracted from hypo- and hyper-thyroid patients from Yazd province was carried out and as shown in Table 1, three types of genotypes were observed in present cases; homozygote (TT), heterozygote (TC) and homozygote (CC). Homozygote (TT) cases exhibit no disease symptoms, heterozygote (TC) cases show mild symptoms; while homozygote (CC) cases show severe thyroid dysfunction symptoms. According to the RFLP-PCR results, 59 cases were homozygotes (TT), 40 cases heterozygotes (TC) and 1 case was recorded to be homozygote (CC). In this study, there were 80 ( $n=60$ hypothyroid and $n=20$ hyperthyroid) patient cases and 20 normal cases. A total of 25 cases comprised of homozygote (TT) hypothyroid females, 20 heterozygote (TC) hypothyroid females, 7 homozygote (TT) hypothyroid females. While, 7 heterozygote (TC) hypothyroid males and 1 homozygote (CC) hypothyroid male case were also observed in this study. While, RFLP-PCR results showed 7 heterozygote (TT) hyperthyroid females, 8 cases of heterozygote (TC) hyperthyroid females, 3 homozygote (TT) hyperthyroid males and 2 heterozygote (TC) hyperthyroid males.

Allele and genotype analysis. The distribution of genotype frequencies for SNP s2268458 as case-control association analysis has been shown in Table 2. The major allele TT genotype in s2268458 of TSHR gene was observed in 42 patients and 17 normal individuals. While, the major allele CC genotype in s2268458 was observed 1 patient and the normal individuals did not show this genotype. A mong 100 cases, 80 cases were patients and 20 cases were normal. In total, there were 59 TT, 40 TC and 1 CC. Among TT cases, 42 of them were patients and 17 of them were normal cases. Among TC cases, 37 of them were patients and 3 of them were normal cases. There was just one CC case that was a patient.According to Table 3 , Among the 100 tested cases, 75 cases were female and 25 cases were male. 59 cases were TT, 40 cases were TC and one case was CC. Among TT cases, 46 cases were female and 13 cases were male. Among TC cases, 29 cases were female and 11 cases were male. Just one case was CC that was a male. Accordintgto Table 4, our analysis on 60 hypothyroidism and 20 hyperthyroid cases showed that 42 cases had TT genotype, 37 cases were TC and 1 case was CC. Among TT cases, 32 cases were hypothyroid and 10 cases were hyperthyroid. Among TC cases, 27 cases were hypothyroid and 10 cases were hyperthyroid. And one CC was observed to be hypothyroid.

\section{Discussion}

During the present study, hypothyroidism was the most frequent thyroid problem among our patients but these results are not in accordance with all studies [19, 20] but has a coordination with some [21]. In Iran, legislation of using iodized salt was established in 1994, however goiter and urinary iodine concentration remained elevated in many Iranian provinces. A previous population-based study assessed the prevalence of hypothyroidism in Isfahan, Iran. They found that hypothyroidism was common (12.8\% of women and $4.7 \%$ of men) and probably due to autoimmunity with no correlation to iodine intake [22]. It seems that the higher frequency of concomitant hypothyroidism may be due to endemy of hypothyroidism in our country. However, whether this difference is due to geographic distribution of thyroid problems or genetic or environmental difference among nations should be elucidated in well structured ecologic studies. Present study confirmed previous reports in which female gender was described as the most frequent one among hypothyroid and hyperthyroid patients. In our study, the mean age of women with MG was lower than men [23-25], however, these results were not statistically significant. Our study did not show gender difference in ages less than 20, however, till 60 years of age, female gender was the most frequent one among patients and thereafter, men were the most common presenting gender too. These findings are in accordance with previous studies [16, 25-27]. Since, 20-50 years is the reproductive period of women and before climacteric period, we hypothesize that the specific hormonal balance may have a role in presentation of clinical features of MG patients possibly as an exacerbating factor. Our study did not show any clinical presentation difference among MG patients with and without thyroid problem as well no paraclinical assessment (EMG, RNS, AchR-Ab) difference was found between these two groups. Whether these findings are pure clinical finding or a consequent of not having enough study subjects remain to be elucidated by future studies with more patients. AITD is characterized by immunogenicity of the major thyroid antigens (Tg, TSHR and TPO) [28]. The study of intronic polymorphisms has been entertained because we now know that intronic DNA may be responsible for regulatory small RNAs as well as providing and/or influencing different start sites for TSHR mRNA generation [29]. The thyroid cells express a variety of TSHR mRNA splice variants [30], indicating that SNPs or small RNAs in this intronic DNA may be important in the generation of different receptor forms and/or their control. Recently, a study from Singapore demonstrated an association of a TSHR intron 1 SNP with GD [31]. SNPs in intron 7 of the TSHR were also found to be associated with GD in Japanese [32], and SNPs in intron 1 of the TSHR were reported to be associated with GD in Caucasians[16]. So the result is, there is an association between $r$ s2268458 with hypothyroidism and it has been confirmed that the allel $\mathrm{C}$ has a pathogenic effect on recessive, dominant and codominant but the biggest effect is on recessive allel and it has been perceived that the allel $\mathrm{C}$ is a pathogenic allel which is usually heritated more in a recessive pattern [12] In this study, homozygote cases (TT) will not show the symptoms and they only have a 162 bp band, heterozygote cases (TC) show some of the symptoms or some light symtoms and they have 3 bands: 162, 100 and 62 but the homozygote cases (CC), show sever symptoms and they have 2 bands 100 and 62 bp which agrees with the Iraq's study who reported that TSHR rs2268458 polymorphisms were associated with hypothyroidism [12] and disagrees with the Lebanon's study who reported that TSHR rs2268458 polymorphisms were not associated with hypothyroidism and hyperthyroidism [23]

According to [17], there was a correlation between relapse of Graves disease and CC genotype of TSHR gene on the rs2268458 of intron 1 [17]. In a study, related to thyroid disease association with polymorphism in Iraq, 73 cases were homozygote (TT), 20 casese were heterozygotes (TC) and 1 case was homozygote (CC) and since all the reseach was done on females, the homozygote(CC) case was a woman [12] but in this study, both men and females were involved and the homozygote case(CC) was a man. This shows a homozygote case(CC) can be seen in both females and men provided, both genders are studied and a large number of people are involved in the study. 


\section{Conclusion}

To our knowledge, this is the very first study showing an association of TSHR gene rs2268458 polymorphism with hypothyroidism and hyperthyroidism in Iran and particularly in Yazd province. In this study, it has been shown that rs2268458 leads to a high risk in having hypothyroidism and hyperthyroidism, particularly hypothyroidism and since in yazd province some other factors such as smoking, stress, bad eating habits, not exercising and so on are high, rs2268458 is more highlighted and it leads to more number of thyroid related diseases such as hypothyroidism and hyperthyroidism. Besides, it has been confirmed that thyroid disorders are more commom among females as men.

\section{Declarations}

\section{Acknowledgements}

The authors are grateful to the financial support of Research and Science Foundation of Science and Arts University, Yazd, Iran.

\section{Conflict of interest}

The authors declare no conflict of interest.

\section{References}

1. Amouzegar, A., Mehran, L., Takyar, M., Abdi, H., Azizi,F. Tehran Thyroid Study (TTS): Int J Endocrinol Metab. 2018; $16(4$ (Suppl)):e84727.

2. Alzahrani, AS., Al Mourad, M., Hafez, K. et al. Diagnosis and Management of Hypothyroidism in Gulf Cooperation Council (GCC) Countries. Adv Ther. 2020;37(7):3097-3111.

3. Hollowell, JG., Staehling, NW., Flanders, WD., Hannon, WH., Gunter, EW., Spencer, CA., Braverman, LE. J Clin Endocrinol Metab. 2002; 87(2):489-99.

4. Chaker, L., Bianco, AC., Jonklaas, J., Peeters, RP. Hypothyroidism. Lancet. 2017;390(10101):1550-1562.

5. Effraimidis, G., Strieder,TG., Tijssen, JG., Wiersinga, WM. Natural history of the transition from euthyroidism to overt autoimmune hypo- or hyperthyroidism: a prospective study. Eur J Endocrinol. 2011; 164(1):107-13..

6. Inskip, PD., Veiga, LHS., Brenner, AV. et al. Hypothyroidism after Radiation Therapy for Childhood Cancer: A Report from the Childhood Cancer Survivor Study. Radiat Res. 2018;190(2):117-132.

7. Wiersinga, WM. Paradigm shifts in thyroid hormone replacement therapies for hypothyroidism. Nat Rev Endocrinol. 2014; 10(3):164-74.

8. Davies, TF., Ando, T., Lin, RY., Tomer, Y., Latif, R. Thyrotropin receptor-associated diseases: from adenomata to Graves disease. J Clin Invest. 2005; 115(8):1972-83.

9. Davies, TF., Yin, X. and Latif, R.The Genetics of the Thyroid Stimulating Hormone Receptor: History and Relevance. Thyroid, 20 (7).2010; 20(7): 72736.

10. Panicker,V. Genetics of Thyroid Function and Disease, 2011 Nov; 32(4):165-175.

11. Peeters, RP. and Toor,HV. Polymorphism in Thyroid Hormone Pathway Genes Are Associated With Plasma TSH and lodothyronine Levels in Health Subjects, 2003; 88(6):2880-8.

12. Hussain, BI. and Hadi, MA. The association of TSHR Gene rs2268458 Polymorphism with Hypothyroidism in Females of Babylon Province- Iraq, 2018; 6:7-18.

13. Stefan, M., Faustino, LC. Genetics of Thyroid -Stimulating Hormone Receptor-Relevance For Autoimmune Thyroid Disease 2017; 8:57

14. Zhang, J., Lazar, MA. The Mechanism of Action of Thyroid Hormones. 2000; 62: 439-66.

15. Baskin, HJ., Cobin, RH. et al. 2002; 8(6)457-69.

16. Dechairo, BM., Zabaneh, D., Collins, J., Brand, O., Dawson, GJ., Green, AP., Mackay, I., Franklyn, JA., Connell, JM., Wass, JA., Wiersinga, WM., Hegedus, L., Brix, T., Robinson, BG., Hunt, PJ., Weetman, AP., Carey, AH., Gough, SC. Association of the TSHR gene with Graves' disease: the first disease specific locus. Eur J Hum Genet. 2005; 13(11):1223-30.

17. Eliana, F., Suwondo, P., Asmarinah, A., Harahap, A., Djauzi, S., Prihartono, J., Pemayun, TGD. The Role of Cytotoxic T-lymphocyte-associated Protein 4 (CTLA-4) Gene, Thyroid Stimulating Hormone Receptor (TSHR) Gene and Regulatory T-cells as Risk Factors for Relapse in Patients with Graves Disease. Acta Med Indones. 2017; 49(3): 195-204.

18. Olatinwo, A., Olurotimi, F. Isiaka-Lawal S. (2009). Thyroid Diseases In Pregnancy: A Review. East African medical journal. 2009; 86: 37-40.

19. Kiessling, WR., Finke, R., Kotulla, P., Schleusener, H. Circulating TSh-binding inhibiting immunoglobulins in myasthenia gravis. Acta Endocrinol (Copenh) 1982;101:41-46.

20. Maclean, B., Wilson, JA. See-saw relationship between hyperthyroidism and myasthenia gravis. Lancet. 1954; 266:950-3.

21. Sahay, BM., Blendis, LM., Greene, R. Relation between myasthenia gravis and thyroid disease. Br Med J. 1965; 1:762-5.

22. Aminorroaya, A., Janghorbani, M., Amini, M., Hovsepian, S., Tabatabaei, A., Fallah, Z. The prevalence of thyroid dysfunction in an iodine-sufficient area in Iran.Arch Iran Med. 2009; 12(3):262-70. 
23. Al-Azzam, SI and Alzoubi, KH. The associations of polymorphisms of TSH receptor and thyroid hormone receptor genes with L-thyroxine treatment in hypothyroid patients. 2014 Jul-Sep; 13(3): 389-97.

24. Xiong, H. and Wu, M. Genetic associations of the thyroid stimulating hormone receptor gene with graves diseases and graves ophthalmopathy: A meta-analysis. 2016.

25. Dong, D., Chong, M.Kc., Wu, Y. et al. Gender differences in quality of life among patients with myasthenia gravis in China. Health Qual Life Outcomes. 2020 3;18(1): 296.

26. Kalb, B., Matell, G., Pirskanen, R., Lambe, M. Epidemiology of myasthenia gravis: a population-based study in Stockholm, Sweden. Neuroepidemiology. 2002; 21(5):221-5.

27. Dresser, L., Wlodarski, R., Rezania, K. and Soliven, B. Myasthenia Gravis: Epidemiology, Pathophysiology and Clinical Manifestations. Manifestations. J. Clin. Med. 2021;10: 2235-2251.

28. Ząbczyńska, M., Kozłowska, K., Pocheć, E. Glycosylation in the Thyroid Gland: Vital Aspects of Glycoprotein Function in Thyrocyte Physiology and Thyroid Disorders. Int J Mol Sci. 2018;19(9):2792.

29. Nakaya, HI., Amaral, PP., Louro, R., Lopes, A., Fachel, AA., Moreira, YB., El-Jundi, TA., da Silva, AM., Reis, EM., Verjovski-Almeida, S. Genome mapping and expression analyses of human intronic noncoding RNAs reveal tissue-specific patterns and enrichment in genes related to regulation of transcription. Genome Biol. 2007; 8(3).

30. Graves,. PN, Davies, TF. New insights into the thyroid-stimulating hormone receptor. The major antigen of Graves' disease. Endocrinol Metab Clin North Am. 2000; 29(2):267-86.

31. Ho, SC., Goh, SS., Khoo, DH. Association of Graves' disease with intragenic polymorphism of the thyrotropin receptor gene in a cohort of Singapore patients of multi-ethnic origins. Thyroid. 2003; 13(6):523-8.

32. Hiratani, H., Bowden, DW., Ikegami, S., Shirasawa, S., Shimizu, A., Iwatani, Y., Akamizu, T. Multiple SNPs in intron 7 of thyrotropin receptor are associated with Graves' disease. J Clin Endocrinol Metab. 2005; 90(5):2898-903.

\section{Tables}

Table 1. RFLP-PCR analysis of hypo-and hyper-thyroid male and female patients

Table 2. Observation of genotype in normal and thyroid disorder cases.

\begin{tabular}{|llll|}
\hline \multicolumn{3}{|c|}{ Genotype } & \\
\hline CC & TC & TT & \\
\hline 1 & 37 & 42 & patient \\
\hline 0 & 3 & 17 & normal \\
\hline 1 & 40 & 59 & total \\
\hline
\end{tabular}

Table 3. Observation of genotype according to gender

\begin{tabular}{|llll|}
\hline \multicolumn{3}{|c|}{ Genotype } & \\
CC & TC & TT & \\
\hline 0 & 29 & 46 & Female \\
1 & 11 & 13 & Male \\
\hline 1 & 40 & 59 & Total \\
\hline
\end{tabular}

Table 4. Observation of genotype according to hypothyroidism/hyperthyroidism disorder

\begin{tabular}{|llll|}
\hline \multicolumn{3}{|c|}{ Genotype } & \\
CC & TC & TT & \\
1 & 27 & 32 & hypothyroidism \\
\hline 0 & 10 & 10 & hyperthyroidism \\
1 & 37 & 42 & total \\
\hline
\end{tabular}




\begin{tabular}{|c|c|c|c|c|c|c|c|c|c|c|c|}
\hline Number & Gender & Disease & Genotype & Number & Gender & Disease & Genotype & Number & Gender & Disease & Genotype \\
\hline 1 & Q & hypothyroid & $\mathrm{TT}$ & 36 & 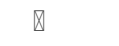 & hypothyroid & TC & 71 & $\nabla$ & hyperthyroid & $\mathrm{TC}$ \\
\hline 2 & ? & normal & $\mathrm{TT}$ & 37 & $\nabla$ & hyperthyroid & TT & 72 & प & normal & $\mathrm{TT}$ \\
\hline 3 & ? & hypothyroid & $\mathrm{TC}$ & 38 & $\nabla$ & hypothyroid & TT & 73 & प & hypothyroid & $\mathrm{TT}$ \\
\hline 4 & ૫ & hypothyroid & $\mathrm{TC}$ & 39 & $\nabla$ & hypothyroid & TT & 74 & 口 & hypothyroid & $\mathrm{TC}$ \\
\hline 5 & $\nabla$ & normal & $\mathrm{TT}$ & 40 & $\nabla$ & normal & $\mathrm{TC}$ & 75 & $\otimes$ & hypothyroid & $\mathrm{TT}$ \\
\hline 6 & $\nabla$ & hypothyroid & $\mathrm{TC}$ & 41 & $\nabla$ & normal & TC & 76 & $\nabla$ & hypothyroid & $\mathrm{TC}$ \\
\hline 7 & $\nabla$ & hypothyroid & $\mathrm{TT}$ & 42 & $\nabla$ & hypothyroid & $\mathrm{TC}$ & 77 & $\nabla$ & hypothyroid & $\mathrm{TC}$ \\
\hline 8 & Q & hypothyroid & $\mathrm{TT}$ & 43 & $\nabla$ & hypothyroid & TT & 78 & $\otimes$ & hypothyroid & TT \\
\hline 9 & ૫ & hypothyroid & $\mathrm{TT}$ & 44 & $\nabla$ & hypothyroid & $\mathrm{TC}$ & 79 & $\otimes$ & hypothyroid & $\mathrm{TC}$ \\
\hline 10 & ? & hypothyroid & $\mathrm{TC}$ & 45 & $\nabla$ & hypothyroid & TT & 80 & $\otimes$ & hypothyroid & $\mathrm{TC}$ \\
\hline 11 & ૧ & hyperthyroid & $\mathrm{TT}$ & 46 & $\otimes$ & hypothyroid & TT & 81 & $\otimes$ & hypothyroid & TT \\
\hline 12 & प & hyperthyroid & $\mathrm{TT}$ & 47 & $\otimes$ & hypothyroid & $\mathrm{TC}$ & 82 & $\otimes$ & normal & $\mathrm{TT}$ \\
\hline 13 & ( & hypothyroid & $\mathrm{TT}$ & 48 & $\nabla$ & hypothyroid & TT & 83 & $\otimes$ & normal & $\mathrm{TT}$ \\
\hline 14 & Q & hypothyroid & $\mathrm{TC}$ & 49 & $\nabla$ & hypothyroid & $\mathrm{TT}$ & 84 & $\otimes$ & normal & $\mathrm{TT}$ \\
\hline 15 & $\nabla$ & hyperthyroid & $\mathrm{TT}$ & 50 & $\nabla$ & hypothyroid & TC & 85 & $\nabla$ & hyperthyroid & $\mathrm{TT}$ \\
\hline 16 & $\nabla$ & hyperthyroid & $\mathrm{TC}$ & 51 & $\nabla$ & hypothyroid & TT & 86 & $\nabla$ & hyperthyroid & $\mathrm{TC}$ \\
\hline 17 & $\otimes$ & hypothyroid & $\mathrm{TT}$ & 52 & $\nabla$ & normal & TT & 87 & $\nabla$ & hyperthyroid & TT \\
\hline 18 & 口 & hypothyroid & TT & 53 & $\nabla$ & normal & TT & 88 & $\otimes$ & normal & $\mathrm{TT}$ \\
\hline 19 & 口 & hypothyroid & TT & 54 & $\nabla$ & normal & TT & 89 & $\nabla$ & hyperthyroid & $\mathrm{TT}$ \\
\hline 20 & ? & hypothyroid & $\mathrm{TC}$ & 55 & $\nabla$ & hypothyroid & TT & 90 & $\otimes$ & hyperthyroid & $\mathrm{TC}$ \\
\hline 21 & ? & hypothyroid & $\mathrm{TT}$ & 56 & $\nabla$ & hypothyroid & $\mathrm{TC}$ & 91 & $\otimes$ & normal & TT \\
\hline 22 & ૧ & hypothyroid & TT & 57 & $\nabla$ & hypothyroid & TC & 92 & $\otimes$ & hyperthyroid & TC \\
\hline 23 & ૫ & hypothyroid & $\mathrm{TT}$ & 58 & $\nabla$ & hypothyroid & $\mathrm{TC}$ & 93 & $\otimes$ & hyperthyroid & TT \\
\hline 24 & प & hyperthyroid & $\mathrm{TC}$ & 59 & $\nabla$ & hyperthyroid & $\mathrm{TC}$ & 94 & $\nabla$ & normal & TT \\
\hline 25 & $\square$ & hyperthyroid & $\mathrm{TC}$ & 60 & $\otimes$ & hypothyroid & $\mathrm{TC}$ & 95 & $\nabla$ & hyperthyroid & $\mathrm{TC}$ \\
\hline 26 & Q & hyperthyroid & $\mathrm{TT}$ & 61 & $\nabla$ & hypothyroid & TT & 96 & $\otimes$ & normal & $\mathrm{TT}$ \\
\hline 27 & ૫ & hypothyroid & $\mathrm{TT}$ & 62 & $\nabla$ & hypothyroid & $\mathrm{TC}$ & 97 & $\nabla$ & normal & $\mathrm{TT}$ \\
\hline
\end{tabular}




\begin{tabular}{|c|c|c|c|c|c|c|c|c|c|c|c|}
\hline 28 & प & hypothyroid & $\mathrm{TC}$ & 63 & $\otimes$ & hypothyroid & $\mathrm{CC}$ & 98 & $\otimes$ & normal & TT \\
\hline 29 & प & hypothyroid & TT & 64 & $\otimes$ & hypothyroid & $\mathrm{TC}$ & 99 & $\otimes$ & hypothyroid & TT \\
\hline 30 & $\nabla$ & hypothyroid & TT & 65 & 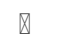 & hypothyroid & TT & 100 & $\nabla$ & normal & TT \\
\hline 31 & ? & hyperthyroid & $\mathrm{TC}$ & 66 & $\nabla$ & hypothyroid & $\mathrm{TC}$ & & & & \\
\hline 32 & प & hypothyroid & $\mathrm{TC}$ & 67 & $\nabla$ & hypothyroid & $\mathrm{TC}$ & & & & \\
\hline 33 & प & hypothyroid & $\mathrm{TT}$ & 68 & $\nabla$ & normal & $\mathrm{TC}$ & & & & \\
\hline 34 & प & hypothyroid & TT & 69 & $\otimes$ & normal & TT & & & & \\
\hline 35 & प & hypothyroid & $\mathrm{TC}$ & 70 & $\nabla$ & hyperthyroid & TT & & & & \\
\hline
\end{tabular}

\section{Figures}
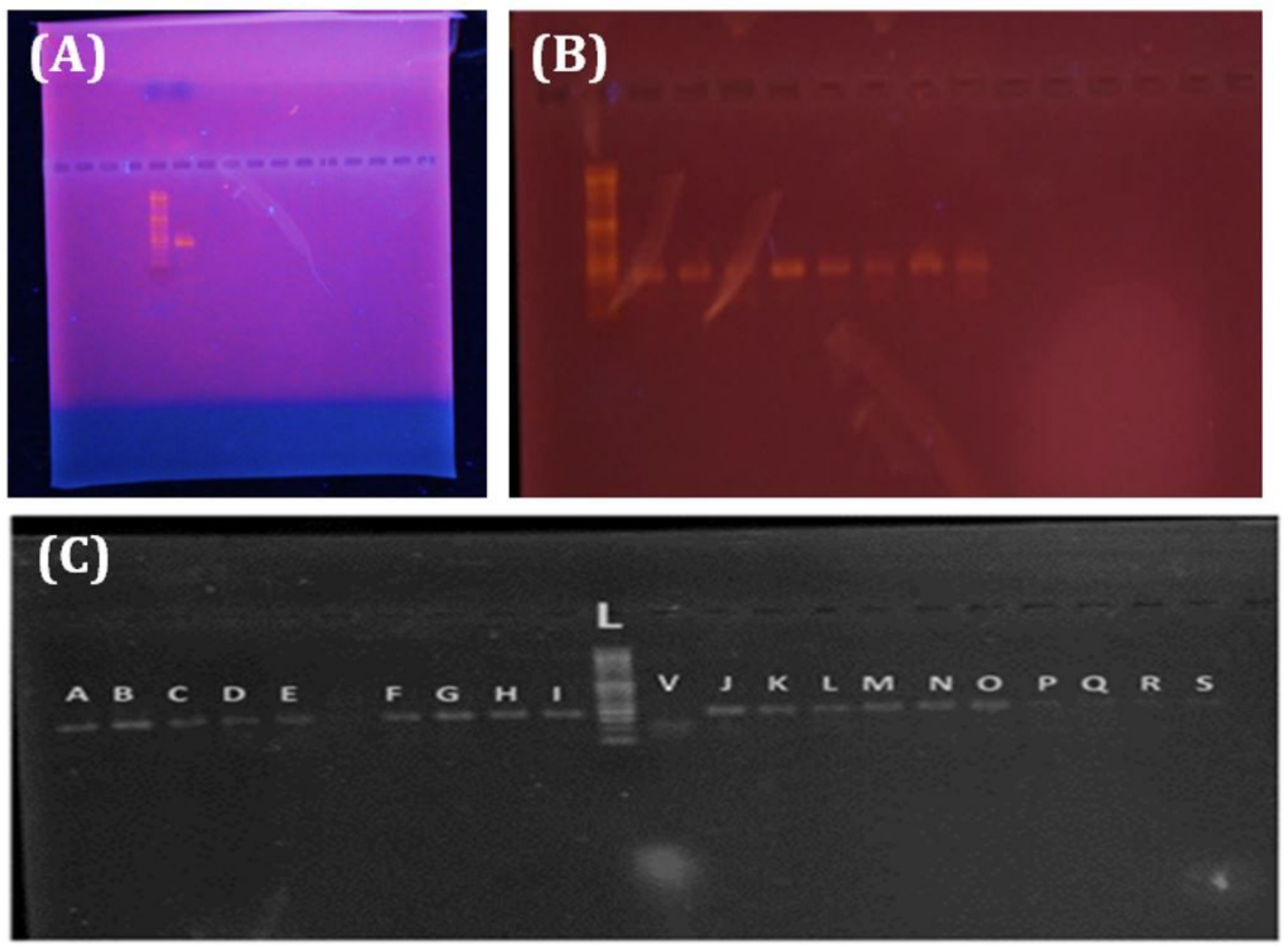

Figure 1.

Figure 1

(A) The pattern of electrophoresis gel of extracted DNAs. (B) The pattern of PCR product of TSHR gene fragment and (C) The pattern of PCR products on agarose gel electrophoresis, related to TSHR gene (162 bp band) after being restricted by Alu I enzyme. The normal casese (B, C, N, $O$ and $P$ ), the hyperthyroid cases(F and R) and the hypothyroid cases (A, D, E, G, H, I, V, J, K, L, M and S). Heterozygote genotypes (TC) with 162,100 and 62 bp bands: 
(D, E, F, G, I, J, L, N, M and S). Homozygote genotypes (TT) with a 162 bp band (A, B, C, H, K, O, P, Q and R). Homozygote genotype (CC) with 100 and 62 bp bands $(\mathrm{V})$.

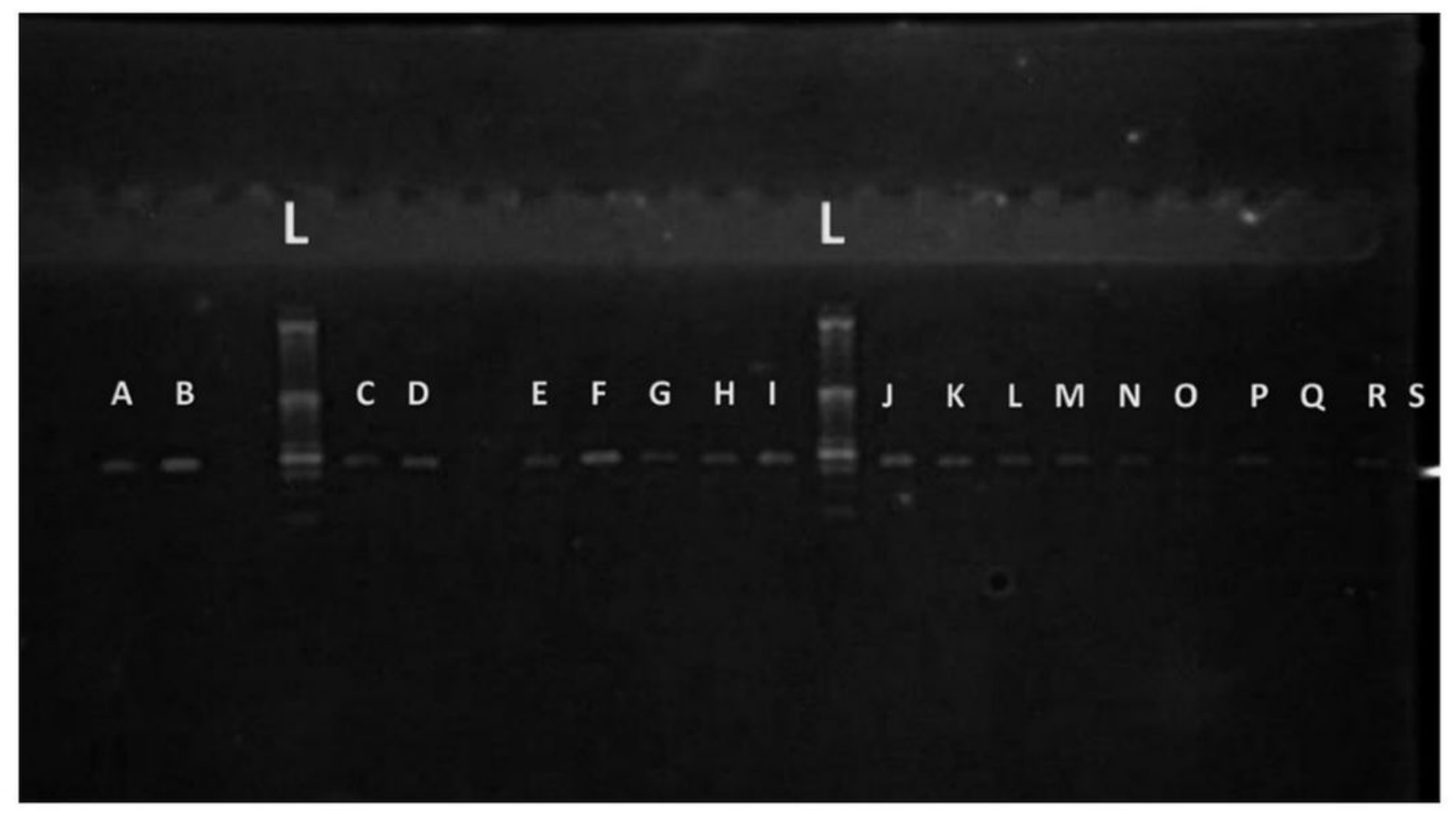

Figure 2.

Figure 2

The pattern of PCR products on agarose gel electrophoresis, related to TSHR gene (162 bp band) after being restricted by Alu I enzyme. The Q, O, N, K, J, I, G, E, C and B cases with heterozygote genotype (TC) have 162, 100 and 62 bp bands. The R, P, M, L, F, D and A cases with homozygote genotype (TT) have 162 bp band.

\section{Supplementary Files}

This is a list of supplementary files associated with this preprint. Click to download.

- GraphicalAbstract.jpg 